Oliver Hahn, Uwe Golle, Carsten Wintermann, Domenico Laurenza

\title{
Scientific Analysis of Leonardo's Manuscript with Anatomic Drawings and Notes
}

\begin{abstract}
In this paper, we discuss the importance of scientifically investigating cultural artefacts in a non-invasive way. Taking as test case Leonardo da Vinci's Manuscript with anatomic drawings and notes, which is stored in Weimar, we clarify fundamental steps in the chronology of this folio. By means of microscopy, infrared reflectography, UV photography, and X-ray fluorescence analysis, we were able to identify various types of sketching material and several varieties of iron gall ink. For his sketches, Leonardo used two different sketching tools, a lead pencil and a graphite pencil, as well as several types of ink for developing these sketches into drawings. With regard to ink, it is important to observe that there is no difference between the ink Leonardo used for drawing and the ink he used for writing text. Based on the materials analysed, we suggest a chronology for the creation of this unique folio.
\end{abstract}

\section{Introduction}

The particular manuscript with anatomic drawings and notes ${ }^{1}$ that is now kept in the Klassik Stiftung Weimar ${ }^{2}$ originally belonged to the Royal Collection in Windsor (Anatomic manuscript B or Fogli B). ${ }^{3}$ It is unclear how this folio - formerly part of the Anatomy B folios, related to RL 19095, and facing RL 19052 - made its way to Weimar. ${ }^{4}$ There might be a connection to Johann Wolfgang von Goethe, who was also interested in anatomical study, especially in studies of skulls. ${ }^{5}$ It would be interesting to consider whether this manuscript came to Weimar at Goethe's urging. ${ }^{6}$

1 See also Keele 1983.

2 Favaro 1928.

3 Keele and Pedretti 1980, 164-167, 820-822, 830; Clayton and Philo 1992, 74-76; Pedretti 2005, 165-178.

4 Steinitz 1960, Möller 1930.

5 Marmor 1988.

6 Mildenberger et al. 2016. 


\section{Current state of research}

Most scholars date the drawing to about $1506-1508,{ }^{7}$ which seems to be confirmed by the hatched areas. During the 1490s, hatching along the outline and within the figure was done with straight lines. ${ }^{8}$
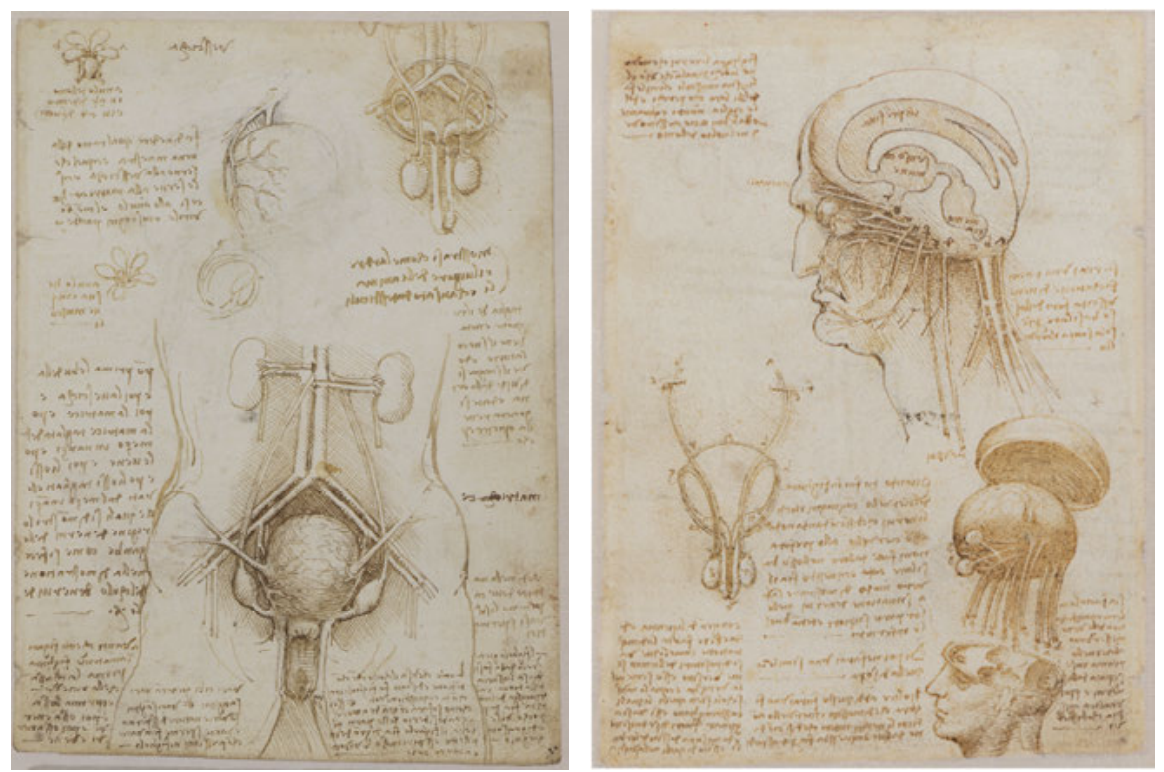

Fig. 1: Presentation of the recto (left) and verso side (right) of the folio. Recto, upper half, from the right: frontal view of male genitalia; bladder (also dissected), muscles of the anal sphincter. Lower half: frontal view of female genitalia. Verso, above: brain with cerebral ventricles, emergence of the spinal cord (flanked by two small cords), cranial nerves. Cranial nerves illustrated (top to bottom): the olfactory nerves directed toward the frontal sinus, the optic chiasm with nerves and optical tracts, the trigeminal branches, the vagus nerve. Lower right: exploded view of the head, with the cranial vault, brain with cranial nerves, and the cranial base. Lower left: frontal view of the male genitalia. (C) Uwe Golle, Carsten Wintermann, Klassik Stiftung Weimar.

The contents of this folio are dominated by scholastic analogical thought, which, after centuries of verbal expression, finds a formidable visual expression

7 Müntz 1899, 526.

8 See also Herrlinger 1953. 
for the first time in Leonardo. There are two main sets of analogies here: the analogies between male and female genitalia, and the analogies between the reproductive and nervous systems. On the recto side of the folio, the female genitalia (below) are coupled with the depiction of the male genitalia (upper right), both presented in a frontal view. On the Windsor folio (RL 19059v; K/P $54 \mathrm{v}$ ), which originally opposite the recto side of the Weimar folio, both images are again paired in a side view ${ }^{9}$. A notation on the Weimar folio highlights the analogy: 'The female has two sperm ducts in the form of testicles, and her sperm is first blood like that of the man [...]' Scholastic medicine described the female genital organs as being analogous to male organs, except that the female organs are internal.

Our main task is not an art-historical interpretation of the drawings, which have been described in detail elsewhere and do not require further interpretation here. Rather, based on the physically available materials, we shed light on the genesis of the folio and thus the relationship between text and drawing.

\section{Scientific analysis}

In summary, the focus of this paper is the material aspects of the folio and the findings of scientific analysis. The drawing and the text passages were executed in different iron gall inks. As mentioned above, visual inspection reveals at least two different colours; a closer investigation reveals what appear to be additional different ink colours (see Fig. 2). Moreover, traces of preliminary sketches are visible to the naked eye.

9 Keele 1983, 66-67, 350-351. 

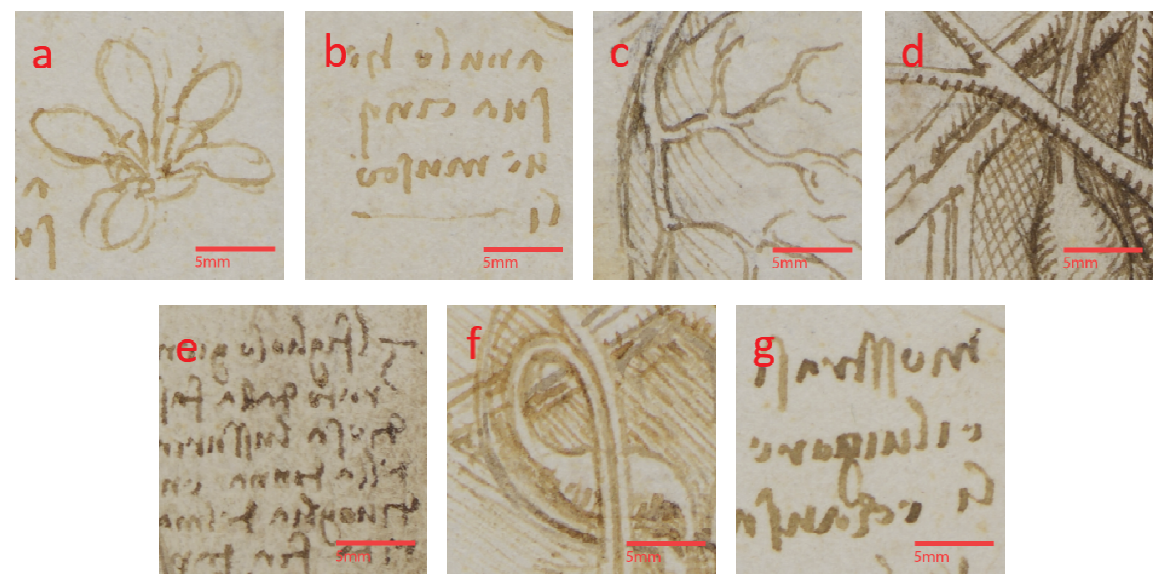

Fig. 2: Detailed views of different parts of the sheet, showing what appear to be different ink colours. These 'differing colours' may in fact be caused by the presence (or absence) of materials used in preliminary sketches or by corrosion processes.

Because the folio is unique and fragile, it must be kept in a controlled environment and cannot be moved. In addition, any analysis of its composition must be conducted without taking samples and without touching the surface of the object. We therefore used UV photography (UV), infrared reflectography (IRR), and $\mathrm{X}$-ray fluorescence analysis to investigate the drawings and text passages (see Appendix).

\section{First results}

\subsection{UV/IRR}

Figure 3 displays various microscopic images taken of several details under UV, VIS, and NIR light. Due to their tannin content, iron gall inks are clearly visible under UV light, whereas the preliminary sketches are visible under NIR illumination. 

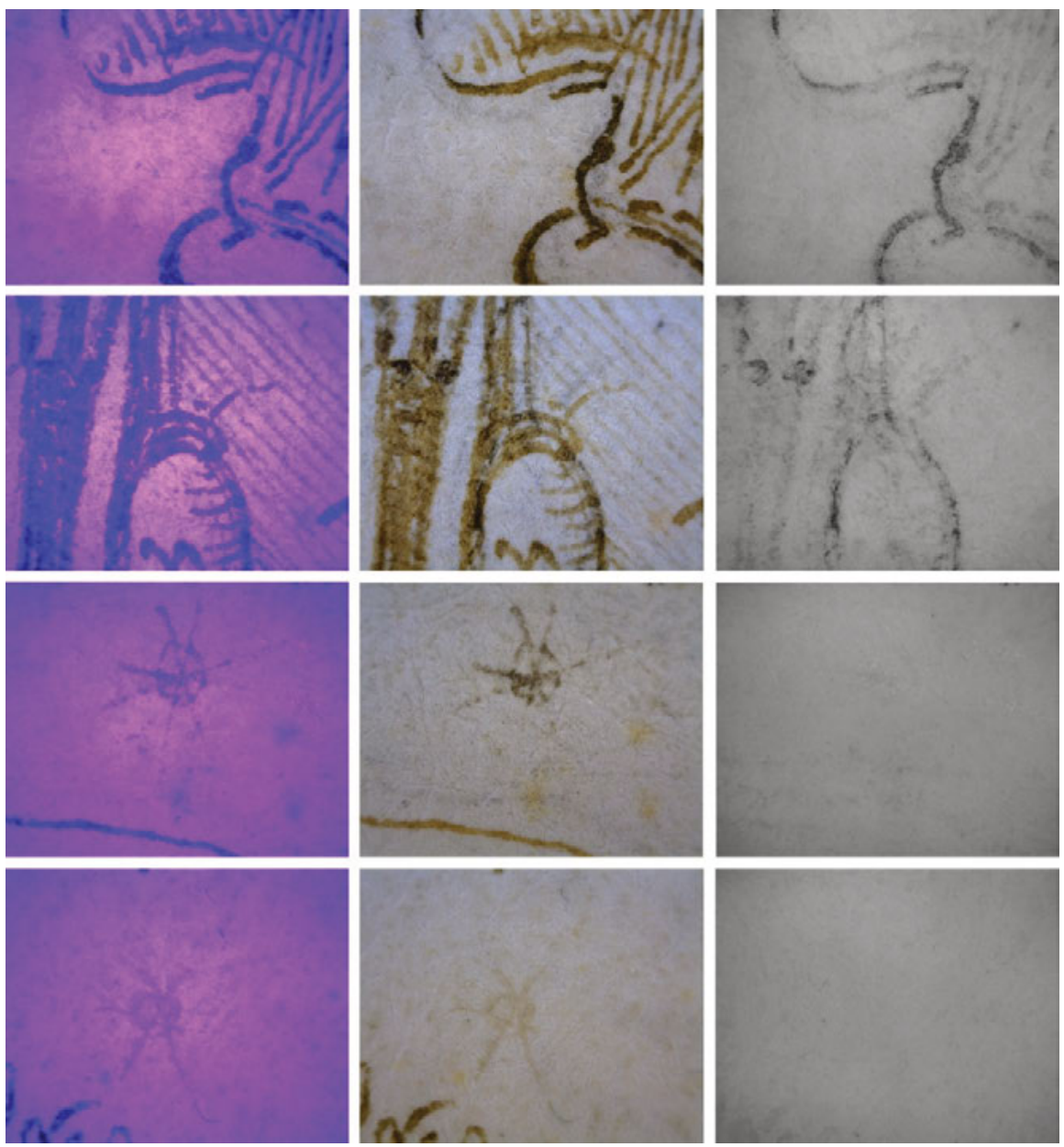

Fig. 3: Microscopic images taken under UV light ( $365 \mathrm{~nm}$, first column), visible light (second column), and NIR light (third column). First row: part of a man's head; second row: part of a male genital organ; third row: star-like marker on the verso side; last row: star-like marker on the recto side. In contrast to IR radiation, UV light is easily absorbed by tannins and increases the visibility of iron gall inks. In addition to the drawings and text passages, elements such as the star-like patterns are visible under UV light.

Infrared reflectography (IRR) of both pages clearly reveals preliminary sketches beneath the various drawings. However, not all parts exhibit sketches (Fig. 4). On the recto side, preliminary sketches of female genital organs (front view) and a bladder (side view) are clearly visible. In contrast to these drawings, the 
drawings of the male genital organs and the five muscles of an anus do not appear to be based on any preliminary sketches. In addition, another preliminary sketch below the bladder drawing was not elaborated.

On the verso side, we can observe preliminary sketches of a man's head with brain (side view), the figure of the top of a skull with brain and related nerves (side view), and the male genital organs (front view). Therefore, a similar pictorial object was sketched in one case but not in the other.
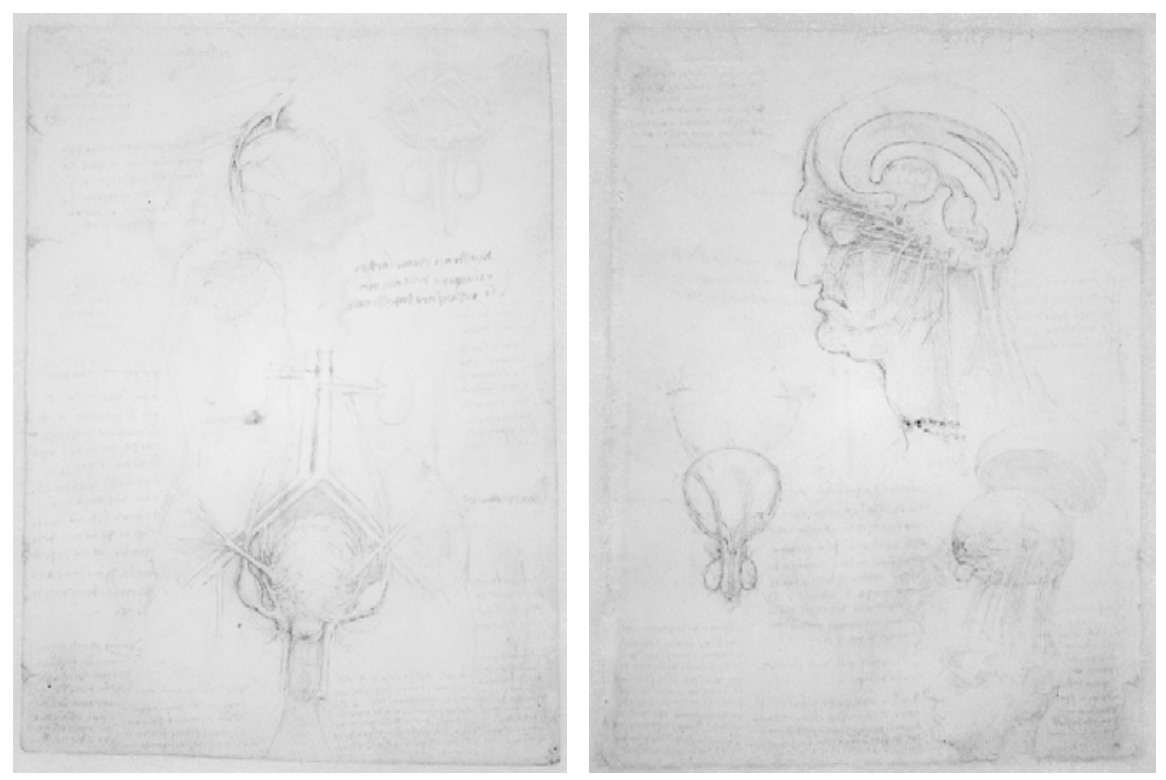

Fig. 4: IRR (1000 nm) of recto (left) and verso side (right).

It is remarkable that we were able to detect the element lead $(\mathrm{Pb})$ in various amounts irregularly disseminated throughout the paper. An elaborate analysis by means of XRF reveals two different types of material for sketching. In the upper parts of each side, Leonardo used a carbon-based material (i.e. a graphite pencil), whereas the lower parts of each side were executed with a lead pen. It is impossible to say why Leonardo used two different types of material for sketching (see Fig. 5). Furthermore, we cannot reconstruct the chronology of the preliminary sketches based on the analytical results, which were conducted on only one object. 

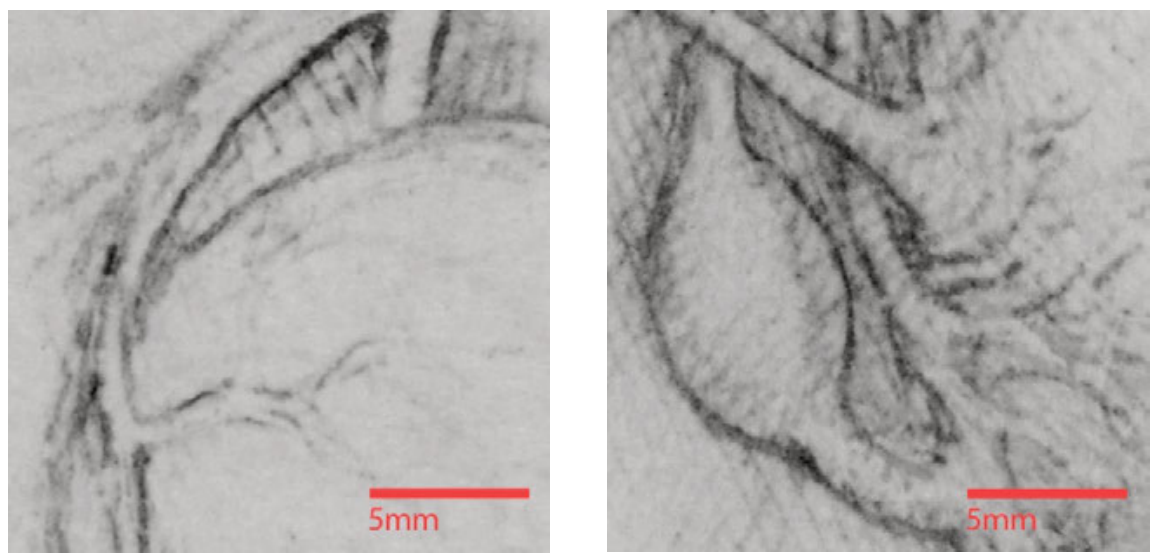

Fig. 5: Detailed views of two different preliminary sketches under IR light (1000 nm) - left: graphite pencil; right: lead pen.

\subsection{XRF}

Investigation of the iron gall ink by means of XRF shows that three different types of ink were used for the drawings and the text passages. In addition, we analysed two iron gall inks that were used for the stars and the pagination character $y$. It must be emphasized that the star-like markers on the recto side are nearly washed out (in contrast to the verso side); these measurements therefore contain a significant measuring error. Nevertheless, it is possible to prove the similarity of the ink used for these markers.

Figure 6 displays, in different colours, the elements of the different groups of iron gall ink. Leonardo did not restrict himself to two types of ink for the drawings and text passages. The two visible colours of ink are due either to a chemical reaction or to the mixing of iron gall ink with the sketching material. We were able to identify three different inks, types A, B, and C, in the drawings and text passages; the markers were performed with ink type $\mathrm{D}$; and the pagination character was written with ink type E. 


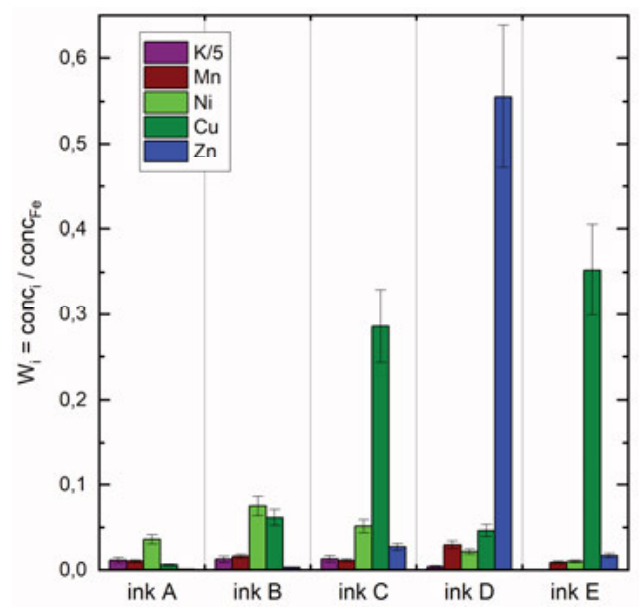

Fig. 6: Fingerprint values (e.g. relative concentration) of different elements (potassium, K; manganese, $\mathrm{Mn}$; nickel, $\mathrm{Ni}$; copper, $\mathrm{Cu}$; zinc, $\mathrm{Zn}$ ) present in the iron gall inks. The error bars indicate analytical error.

Based on the various materials, we can reconstruct the chronology of the two pages. As mentioned before, it is not possible to fix the sequence of the various preliminary sketches based on the analytical results. Nevertheless for the recto side we may conclude that Leonardo first used a lead pencil for the preliminary sketch of the female genital organs and then switched to a carbon-based material, maybe graphite, for the preliminary sketch of the bladder (Fig. 7).
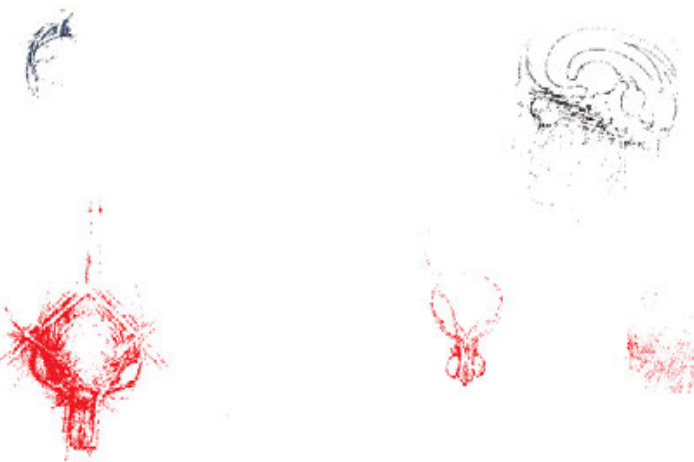

Fig. 7: Reconstruction of the chronology of preliminary drawings (red: lead pen; black: graphite pencil). 
In the next step, most of the drawings and the text passages were executed with one iron gall ink, type A (Fig. 8, brown lines). It must be emphasized that all preliminary sketches (in either led pen or graphite pencil) were then elaborated with this type of ink. After this step, additional parts of the drawings were executed in two different types of ink: type B (Fig. 8, blue) and type C (Fig. 8, green). Finally, the markers (Fig. 8, red) and the pagination (Fig. 8, violet) were added. It is very important to emphasize that Leonardo mostly used the same ink for the drawings and for the text passages.
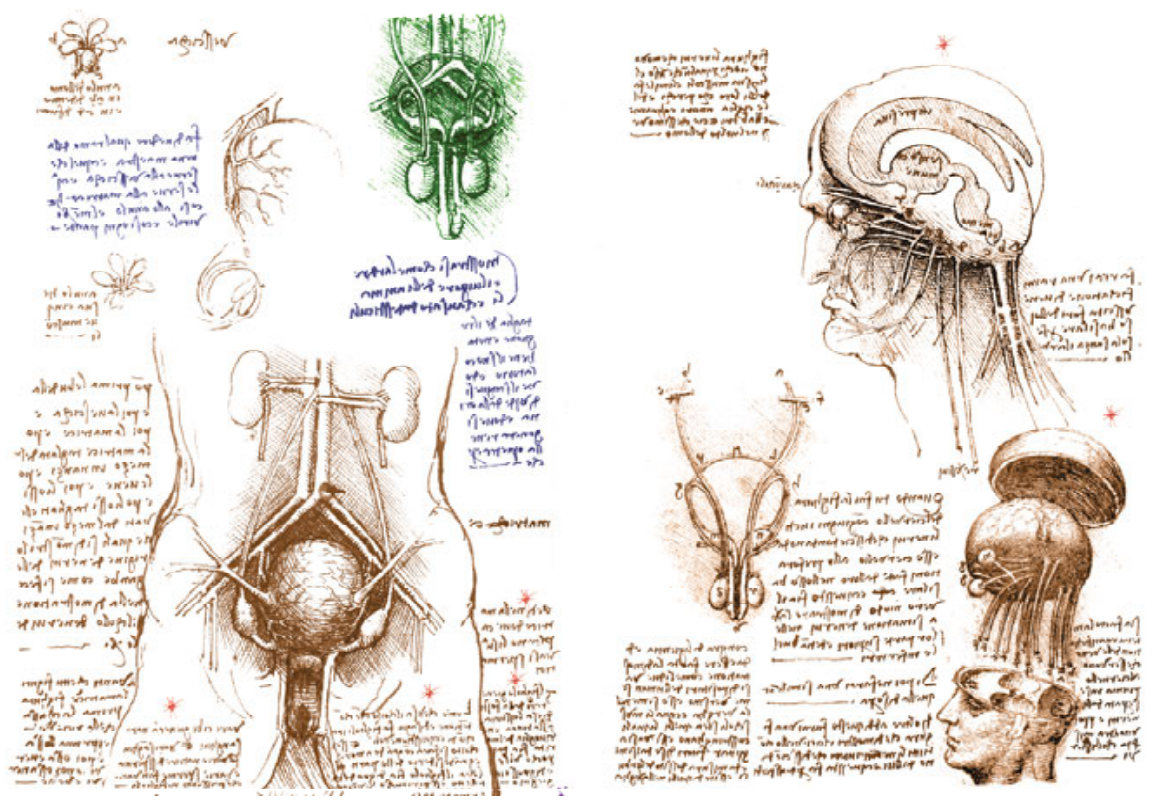

Fig. 8: Reconstruction of the iron gall ink drawings and the text passages.

\section{Conclusion}

Scientific investigation of this folio reveals distinct steps in the chronology of Leonardo's anatomic sketchbook. We have been able to identify various types of sketching material and various types of iron gall ink. Leonardo used two different sketching materials, and he used several inks to develop the sketches into drawings. It is remarkable that there is no difference between the ink used for drawing and the ink used for text. These findings lead to a general interpretation 
of the scientific results, based on different types of hatching corresponding to different functions, and might provide new insights into Leonardo's creative working process.

As mentioned before, the relation of this folio to the bundle of anatomic drawings stored in the Windsor Castle collection is evident. It is noteworthy that we analysed only one folio of the whole codex. To answer broader questions about the use of two different sketching materials, the varying use of ink for drawings and for text passages, and the significance of star-like markers, additional analysis of these objects will have to be conducted.

\section{Excursus}

\subsection{Reconstruction of the primary appearance}

Regarding the chemical composition of iron gall ink, it should be borne in mind that the appearance of the various types of iron gall ink may have changed over time. During the manufacturing process, iron gall ink is black due to the formation of the black ferro-gallate pigment. With age, the colour can change from black to brown, depending on storage conditions, climate, and the chemical composition of the ink itself. These phenomena have been well known for generations and were first described by Ribeaucourt. ${ }^{10}$ On the other hand, paper degrades and turns brown due to oxidation and other corrosion processes. Further details are discussed elsewhere. ${ }^{11}$

Figure 9 shows how the two pages may have appeared originally. The various types of iron gall ink are all black, and the optical interference of the different sketching materials is not visible.

10 Ribeaucourt 1797.

11 Meyer et al. 2015. 

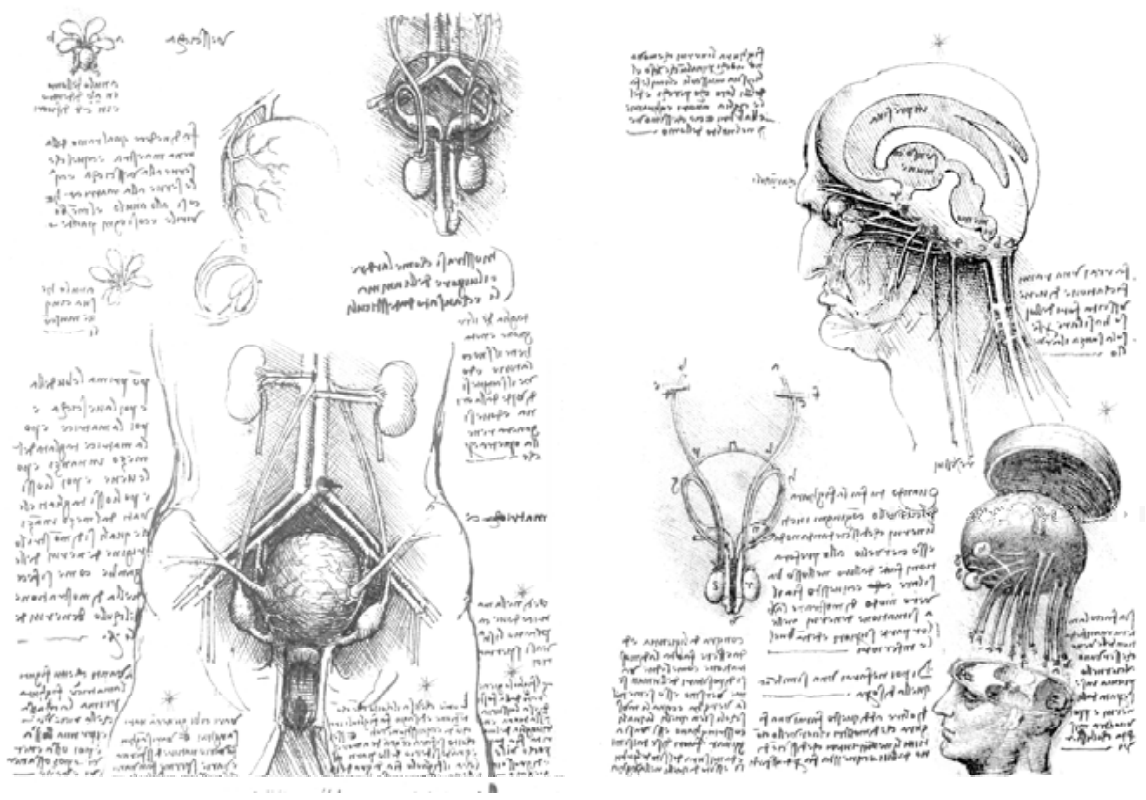

Fig. 9: Reconstruction of the original appearance

\subsection{The paper}

Visually observed under grazing light, the surface of the paper exhibits textile imprints. These imprints are due to the use of wool felt during production of the paper. There is no difference between the recto and verso sides. Therefore, it is not possible to distinguish between a sieve and a felt side. Examination of the folio under transmitted light reveals no watermark; however, two other observations indicate an early type of paper. The rib wires are very broad (up to $1 \mathrm{~mm}$ ). The copper wire was first drawn and then flattened. No weft-wire structure is visible; presumably, the weft wires were not woven in during the construction of the sieve. The rib wires were not fixed, or horsehair was used as weft wire, and the wires are therefore invisible in the paper structure (see Fig. 10). ${ }^{12}$

12 Dietz and Wintermann 2013. 


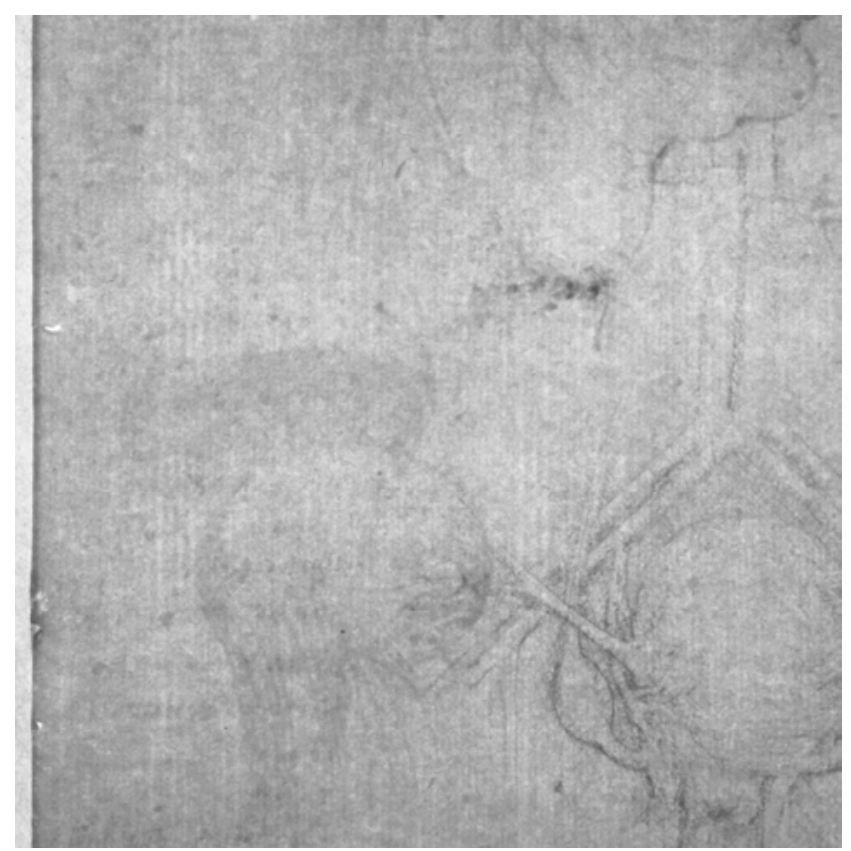

Fig. 10: Visualization of the paper structure.

\section{Appendix}

\section{Multispectral Imaging analysis: UV photography (UV) and Infrared Reflectography (IRR)}

Infrared and UV reflectography are well-established, non-destructive examination tools that can reveal information about a broad range of cultural heritage artefacts. Both techniques may be described as Multispectral Imaging (MSI) techniques.

UVA (320-400 nm) is most commonly used in the examination of artefacts. Some materials absorb UV radiation and re-emit it in the visible spectrum as UV-induced visible fluorescence. UV radiation causes visible fluorescence in various proteinaceous materials such as glue and paper sizing implements and is easily absorbed by tannins.

Infrared radiation used for the examination of cultural artefacts is generally divided into near IR (NIR, 700-1000 nm) and mid IR (MIR, 1000-3000 nm). Many materials exhibit different visual appearances under specific wavelengths 
of IR radiation, depending on whether they absorb, transmit, or reflect the radiation. Most important in these investigations is the behaviour of certain types of ink and drawing media, which enables classification of these materials. Carbonbased ink, graphite, charcoal, and metal points easily absorb in MIR, while organic ink and iron gall ink become increasingly transparent under longer wavelengths. ${ }^{13}$

We used a USB microscope equipped with white light LEDs in addition to the UV (390 $\mathrm{nm}$ ) and near infrared LEDs (NIR, $940 \mathrm{~nm}$ ) (magnification $\times 3.4)$. In addition, the objects were photographed with an X71 Microbox camera under UV (365 nm), normal, and NIR (1100 nm) illumination.

\section{Fingerprint model}

It is well known that iron gall inks are produced by mixing natural iron vitriol with gallnut extracts. Because the inks are made from natural raw materials, they have heterogeneous, often very different, compositions. ${ }^{14}$ In addition to iron sulfate, they contain secondary components, such as vitriols of the aluminum (Al), manganese $(\mathrm{Mn})$, copper $(\mathrm{Cu})$, or zinc $(\mathrm{Zn}),{ }^{15}$ which are also referred to as 'metal salts'. These metals do not contribute to colour formation in the ink solution, but they may change the chemical properties of the inks and influence corrosion processes. The varying composition of these different vitriols is a characteristic property of historical iron gall inks and makes their exact determination possible. ${ }^{16}$

The inorganic contaminants mentioned above provide a basis for differentiating between the iron gall inks. The present micro-XRF measurements of the iron gall inks were quantified using the composition fingerprint model, which is based on fundamental parameter procedures leading to the value $\mathrm{W}_{i}$ (relative amount of weight concentration of the element $i$, e.g. $\mathrm{Mn}, \mathrm{Cu}, \mathrm{Zn}$, relative to Fe). ${ }^{17}$ Ageing phenomena have no influence on the method of analysis we used, because even if the appearance of an iron gall ink has changed (e.g. from black to brown) due to chemical corrosion processes that alter the organic material, the proportion of metal salts in the ink remains the same.

13 Mrusek et al. 1995.

14 Krekel 1999, Oltrogge 2005.

15 Hickel 1963, Lucarelli and Mando 1996.

16 Hahn 2010.

17 Hahn et al. 2004, Malzer et al. 2004. 


\section{X-ray fluorescence (XRF)}

Elemental analyses were carried out with the mobile energy dispersive micro-Xray spectrometer ARTAX ${ }^{\circledR}$ (Bruker $\mathrm{GmbH}$, Berlin), which consists of an aircooled, low-power molybdenum tube, polycapillary X-ray optics (measuring a spot size $70 \mu \mathrm{m}$ in diameter), an electrothermally cooled Xflash detector, and a CCD camera for sample positioning. Additional open helium purging in the excitation and detection paths enables the determination of light elements $(11<\mathrm{Z}<20)$ without a vacuum. All measurements were made using a $30 \mathrm{~W}$ lowpower Mo tube, $45 \mathrm{kV}, 600 \mu \mathrm{A}$, with an acquisition time of $15 \mathrm{~s}$ (live time) to minimize the risk of damage. For better statistics, at least ten single measurements were averaged for one data point. Further details of the method are described elsewhere. ${ }^{18}$

\section{Acknowledgements}

The authors want to thank Christien Melzer (Klassik Stiftung Weimar) and Ursula Verena Fischer Pace (Rome) for fruitful suggestions and discussions.

\section{References}

Bronk, Heike, Stefan Röhrs, Alexej Bjeoumikhov, Norbert Langhoff, Jürgen Schmalz, Rainer Wedell, Hans-Eberhard Gorny, Andreas Herold and Ulrich Waldschläger (2001), 'ArtTAX - a new mobile spectrometer for energy dispersive micro X-ray fluorescence spectrometry on art and archaeological objects', Fresenius' Journal of Analytical Chemistry, 371: 307-316.

Clayton, Martin and Ron Philo (1992/93), Leonardo da Vinci: The Anatomy of Man; Drawings from the Collection of Her Majesty Queen Elizabeth II, Houston: Museum of Fine Arts / Boston: Little, Brown and Co., 1992 [exhibition catalogue].

Dietz, Georg and Carsten Wintermann (2013), 'Wasserzeichen', in Beate Böckem and Gudula Metze (eds), Ars Nova - Frühe Kupferstiche aus Italien: Katalog der italienischen Kupferstiche von den Anfängen bis um 1530 in der Sammlung des Dresdener Kupferstichkabinetts, Petersberg: Imhof, 282-285.

Favaro, Giuseppe (1928-1930), 'Intorno al nuovo foglio anatomico Vinciano del Castello di Weimar', Atti del reale Istituto Veneto di Scienze ed Arti, 89: 765-780.

Hahn, Oliver (2010), 'Analyses of iron gall and carbon inks by means of X-ray fluorescence analysis: A non-destructive approach in the field of archaeometry and conservation science', Restaurator, 31/1: 41-64.

18 Bronk et al. 2001, Hahn et al. 2004, Wolff 2009. 
Hahn, Oliver, Wolfgang Malzer, Birgit Kanngießer and Burkhard Beckhoff (2004), 'Characterization of Iron Gall Inks in Historical Manuscripts using X-Ray Fluorescence Spectrometry', $X$-Ray Spectrometry, 33: 234-239.

Herrlinger, Robert (1953), 'Die didaktische Originalität der anatomischen Zeichnungen Leonardos: ein Beitrag zur Geschichte der anatomischen Abbildung', Anatomischer Anzeiger, 99: 366-395.

Hickel, Erika (1963), Chemikalien im Arzneischatz deutscher Apotheken des 16. Jahrhunderts unter besonderer Berücksichtigung der Metalle, $\mathrm{PhD}$ dissertation, Universität Braunschweig.

Keele, Kenneth D. (1983), Leonardo da Vinci's Elements of the Science of Man, New York: Academic Press.

Keele, Kenneth D. and Carlo Pedretti (1980), Leonardo da Vinci. Atlas der Anatomischen Studien in der Sammlung Ihrer Majestät Queen Elizabeth II in Windsor Castle, 3 vols, Gütersloh: Prisma.

Krekel, Christoph (1999), 'Chemische Struktur historischer Eisengallustinten', in Gerhard Banik and Hartmut Weber (eds), Tintenfraßschäden und ihre Behandlung (Werkhefte der staatlichen Archivverwaltung Baden-Württemberg, Serie A Landesarchivdirektion, 10), Stuttgart: Kohlhammer, 25-36.

Lucarelli, Francesco and Paolo A. Mando (1996), 'Recent applications to the study of ancient inks with the Florence external-PIXE facility', Nuclear Instruments and Methods in Phys. Res. B 109/110: 644-652.

Malzer, Wolfgang, Oliver Hahn, and Birgit Kanngießer (2004), 'A fingerprint model for inhomogeneous ink paper layer systems measured with micro X-ray fluorescence analysis', $X$-Ray Spectrometry, 33: 229-233.

Marmor, Max (1988), ‘Leonardo's “Remarkable Medical Abomination”: an Unpublished Letter by Ottilie von Goethe', Achademia Leonardi Vinci, 1: 96-104.

Meyer, Carla, Sandra Schultz and Bernd Schneidmüller (eds) (2015), Papier im mittelalterlichen Europa. Herstellung und Gebrauch, Berlin: De Gruyter.

Mildenberger, Hermann, Serena Zanaboni, Fernando Mazzocca, Francesca Tasso and Reinhard Wegner (2016), Von Leonardo fasziniert. Giuseppe Bossi und Goethe (Im Blickfeld der Goethezeit, 6), Dresden: Sandstein Verlag, 2016.

Mrusek, Ralf, Robert Fuchs, and Doris Oltrogge (1995), 'Spektrale Fenster zur Vergangenheit. Ein neues Reflektographieverfahren zur Untersuchung von Buchmalerei und historischem Schriftgut', Naturwissenschaften, 82: 68-79.

Möller, Emil (1930), ‘Abbozzi e testi sconosciuti del Vinci sull'anatomia', Supplemento alla Raccolta Vinciana, 13: 1-13.

Müntz, Eugène (1899), Léonard de Vinci. L'Artiste, le Penseur, le Savant, Paris: Hachette.

Oltrogge, Doris (2005), 'Färbetechnik' in A. Bartl, C. Krekel, M. Lautenschlager, and D. Oltrogge (eds), Der 'Liber illuministarum' aus Kloster Tegernsee. Edition, Übersetzung und Kommentar der kunsttechnologischen Rezepte, Stuttgart: Franz Steiner: 638-649.

Pedretti, Carlo (2005), L'anatomia di Leonardo da Vinci fra Mondino e Berengario: ventidue fogli di manoscritti e disegni nella Biblioteca Reale di Windsor e in altre raccolte presentati in facsimile nell'ordinamento cronologico, Florence: Cartei \& Becagli.

Ribeaucourt (1797), 'Über die gewöhnliche schwarze Tinte', Crells chemische Annalen, 28: 41-54.

Steinitz, Kate T. (1960), 'The Leonardo Drawings at Weimar', Raccolta Vinciana, 20:339-349.

Wolff, Timo (2009), Referenzprobenfreie quantitative Mikro-Röntgenfluoreszenzanalyse, PhD dissertation, Technische Universität Berlin. 
